\title{
DIMENSIÓN LÓGICA Y ONTOLÓGICA DE LA VERDAD. LEIBNIZ, DESCARTES
}

$\mathrm{M}^{\mathfrak{a}}$ Socorro Fernández Garcia

(Bilbao)

La magnitud de la obra leibniciana hace que cualquier aspecto que se estudie necesite de una referencia a una totalidad que nunca acaba de agotarse. Entre las peculiaridades que marcan su pensamiento quiero detacar en esta comunicación el modo como articuló la lógica y la metalisica en una cuestión que en la obra leibniciana es de capital importancia: la verdad eterna. ${ }^{1}$ El fin del trabajo es poner de manifiesto la diferencia que existe en este tema entre el filósofo de Hannover y Descartes.

Leibniz necesita defender la autonomia de la verdad paria salir del nominalismo, y también sostendra frente a Descartes la independencia de las verdades eternas respecto a la voluntad de Dios. Las controversias que sostuvo con llobbes y con Locke, asi como sus discrepancias respecto a la postura cartesiana ilustran suficientemente la postura de Leibniz, que defiende que la no contradicción es la condición previa de la verdad. La verdad. desde el punto de vista lógico, tiene para Leibniz las siguientes caracteristicas:

1. Las verdades para Leibniz son absolutamente independientes del sujeto que las conoce, son verdades en si mismas absolutas en la eternidad.

2. Se puede atirmar que Leibniz identifica las verdades de razón con las verdades eternas. Hay numerosos textos que lo muestran, algunos de un modo más claro que otros.

3. Por último, los elementos de la verdad eterna desde el punto de vista lógico se reducen a las definiciones y a las verdades idénticas. Toda verdad necesaria es idéntica, ya explicitamente - verdades primeras o axiomas idénticos- ya virtualmente o implicitamente - teoremas demostrables. Demostrar los teoremas es referirlos a verdades idénticas analizando sus teoremas, definiéndolos. Todas las verdades se reducen a las primeras con el auxilio de las deliniciones o por la reducción de las nociones, en la cual consiste la prueba a priori, independiente de la experiencin. ${ }^{2}$

Por otra parte, la tesis que une el estatuto lógico con el ontológico de la verdad eterna es la que sostiene que estas verdades son pensamientos de Dios; elt esto consiste su realidad objetiva. ${ }^{3}$ Esta afirmación se puede justificar desde dos puntos de vista; en primer lugar, es conocido que Leibniz sitúa el origen de las verdades de razón en el entendimiento; en este sentido afirmará que aunque nuestro espiritu es capaz de conocer todo lipo de verdades (tanto las de razón como las de hecho), él es la fuente de las primeras; ya que por muy numerosas que sean las experiencias que uno posea acerca de una verdad universil, no puede estar seguro de su necesidad por vía de inducción sino sólo por la razón. ${ }^{5}$

I Para un estutio detallado de la rerdad en el pensamiento keibniciana, Citr. FERNÁNDEZ GARCiA, $M^{2}$ SOCORRO., La demostración Leibnicioma de la existencia de Dios por las verktes efornas, en "Excerpta e Dissertationibus in philosophin", III (1993), pp.235-313.

2 Cir. Jbidem, pp.270-271.

3 Cfr. MARTIN, G., Leibniz, Logique ef . Hétaphysique, trad. par M1. Reginier, IBeauclesne, Paris 1966, p. 136.

+ Cfr. Nomeaur Essais (1704-1705), GP.V, Ireface, p. 43.

5 Cfr. Nomeanc Essais (1704.1705), GP.V, 1, I, p. 76. 
En segunda lugar, en la medida que las verdades eternas son los principios reguladores de las existencias deben tener algún tipo de existencia en un ser existente, esto es en el entendimiento de Dios ${ }^{6}$ en donde estas verdades fundan no sólo su existencia sino su posibilidad. ${ }^{7}$ Es en la mente divina donde estas verdades se constituyen como tales y donde primariamente ejercen su tendencia a existir. Esto es asi porque estas verdades estan en Dios como objetos de su entendimiento, no formadas por agregación de partes sino vistas en una sola intuición que las constituye como objetos. ${ }^{8}$

Es obvio que esta concepción leibniciana se aleja de la postura cartesiana. En primer lugar, para Descantes la creación de las verdades eternas es una consecuencia de la libertad absoluta de Dios y una garantia de la autenticidad de las ciencias. ${ }^{9}$ Dios establece unas leyes en la naturaleza lo mismo que un rey crea las leyes en su reino. Estas verdades son metalisicamente contingentes respecto de la libertad de Dios; ${ }^{10}$ dependen exclusivamente de la voluntad divina sin que tenga sentido el que Dios las conozca como necesarias en sí mismas, ya sea en tanto que distintas de El, o en si mismo."l

En segundo lugar, Descartes nos remite siempre a los limites de nuestro entendimiento. No hay nada que nos autorice a afirmar que en Dios, para quien conocer y querer son una sola cosa, haya pensamiento de los posibles; por otra parte, las leyes de un entendimiento linito y creado no pueden ser la medida del ser infinito y creador, ni limitar su omnipotencia. La causalidad, por tanto, no constituye un mundo inteligible donde podamos instaurar nuestros principios lógicos de continuidad o de finalidad.

Para Leibniz, por el contrario, la causa de los fenómenos se resuelve en ratio lógica. Para cualquier inteligencia, cualquier causa no puede ser más que una razón. De este modo lo posible es la medida de lo real; toda causa o idea posible enciersa un efecto posible aunque hay que distinguir que en Dios la posibilidad se encuentra de un modo absoluto y sin límites, de modo que la finitud de los posibles determina la infinitud de los mundos posibles, a pesar de que no todos lleguen a la existencia sino sólo aquellos que son composibles. que son los que realmente se realizarán en el mundo creado.

En Leibniz, la limitación del conocimiento es intensiva;12 conocemos los posibles que están realizados porque han sido puestos por una lógica increada que combina más composibles que los que lleva a la existencia; ${ }^{13}$ a su vez, estas verdades existen en Dios y por Dios pero no dependen de su voluntad. El principio de contradicción es el criterio de existencia necesaria $y$ también suficiente para las verdades a priori; todas las combinaciones de conceptos no contradictorios existen y no hay otros; del mismo modo, toda proposición que se derive de estas combinaciones no contradictorias será verdadera, y esto no supone ninguna traba para la libertad de Dios. 14

6 De esie modo, una vez más la demostración da la existencia de Dios se reduce a ser una mustración de la necesidad de su existencia como fundamento de todo lo posible y de todo lo real.

7 Cfr. De renum originalione radicali (1697), GP.VII, pp. 304-305 y Mlonadologie (1714), GP.VI, p. 614, $1^{\circ} 43$.

8 Cfr. Specimen, GP.VII, p. 309.

9 Cir. ORTIZ, M. T., La creación en Descarses, Memoria de Licenciatura, Pamplona 1986, p. 79, pro mamus. cripto.

10 Cfr. FERNANDEZ RODRIGUEZ, J. L., Las verdades eternas; por quié Malubrance crifico el voluntarismo de Descartes, en “Anuario Filosófico" 16-2 (1983), p. 12.

II CIr. ORTIZ, M. T., Op. cit., p. 89.

12 Cfr. SALAS, J. de., Ráóny Legitimidad en Leibnis. Tecnos, Madrid 1994, pp. 76-83.

13 Cir. BELAVAL. Y., Leibnis, crifique de Descartes, Gallinard, Paris 1960, p. 533-536.

it Cfr. De rerum originatione radicali (1697), GP. VII, p. 304. 